\title{
EDITORIAL
}

\section{IMPACT OF COVID-19 ON ENT PRACTICES}

ENT specialists and surrounding staff are a high-risk group for COVID-19 infection, since they are particularly exposed to viral transmission directly through mucus and aerosolized particles during clinical examination, surgeries, or other interventions in the head and neck area. Evidence from China, Italy, and Iran and recently from the United Kingdom suggests that ENT specialists are among the highest risk group of contracting the SARS-CoV-2 virus, especially when their examinations and procedures are performed without using appropriate personal protective equipment (PPE). Unfortunately, many of our ÅÎO colleagues worldwide are victims of the pandemic. ${ }^{1-5}$.

The World Health Organization (WHO) declared COVID-19 (coronavirus disease) outbreak a global pandemic on March 11, 2020. 6 SARSCoV-2 virus is mainly transmitted between people through respiratory droplets and contact routes. Infected respiratory droplets enter the human body through the nose and mouth. Conjunctiva is also considered to be a potential entrance point, although clear data proving this are not sufficient. Contact transmission by hands occurs through surfaces on which the virus is deposited. Aerosol transmission of the virus is plausible as well; however, doubtful evidence of this is still lacking. For healthcare workers, attention must be paid to all possible modes of transmission by taking appropriate protective and hygiene measures. ${ }^{7-9}$

ENT clinical examination is considered a highrisk medical procedure for the transmission of the SARS-CoV-2 virus. ${ }^{9,10}$ Particularly endoscopic examinations of the nose, sinuses, pharynx, and larynx are considered aerosolgenerating procedures. The virus appears to be present in the upper aerodigestive tract, with very high concentrations in the nasal cavity and nasopharynx compared to the rest of the pharynx . It has also been shown that viral aerosol particles may remain in the air for three, if not more, hours. ${ }^{10}$ Therefore, it is recommended that the precautions adopted for endoscopic examinations of the head and neck should be the same as for other aerosolgenerating procedures.

Depending on the local circumstances, routine, nonurgent appointments should be postponed to limit the chance of virus infection of patients or healthcare professionals. Hence, otolaryngologists should limit their medical care activities to patients with time-sensitive, urgent, and emergent medical conditions ${ }^{10}$ such as head and neck cancers, airway emergencies, head and neck abscesses, acute otitis media, acute mastoiditis, complicated sinusitis, sudden hearing loss, facial paralysis or facial trauma. In any case, the clinical examination should be limited to the absolute necessary diagnostic procedures. Endoscopic examinations should be avoided if possible and should only be indicated if absolutely needed (e.g. increased suspicion or risk of malignancy, airway obstruction). ${ }^{4}$ Regarding rhinologic examination, not only endoscopy but even anterior rhinoscopy should be performed only when absolutely indicated, according to a recommendation. ${ }^{5}$

The use of high level PPE is mandatory when examining a patient confirmed or suspected for COVID-19, in particular during nasal and laryngeal endoscopy. The appropriate PPE in such cases should include high protection mask (FFP2 or FFP3/N95, depending on the source of recommendation), goggles or face shield, gown, surgical cap, and (double) gloves. ${ }^{2,8}$ Physicians are also advised to wear theater clothes (scrubs), whereas a full protection suit is less commonly suggested. The patient himself should wear a mask in such cases. ${ }^{5}$

Correspondence : Professor Dr. Shaikh Nurul Fattah Rumi, Professor and Head, Department of ENT, Dhaka Medical College, Dhaka 
Local decongestants and anesthetics in form of sprays should be avoided, to avoid sneezing and coughing. Instead carefully placed pledgets should be used. ${ }^{4}$ In addition, endoscopy should be performed by video monitoring rather than use of eyepiece, to keep the patient's and health care worker's faces apart.

Additional recommendations indicate that the examination should be performed by the most experienced professional and that the examination should take place in a negative pressure room and only the necessary personnel should be present. If a negative pressure isolation room is not available, endoscopic procedures can be performed in a designated room equipped with a high-performance air cleaning system.

There is broad international consensus that not urgent/emergent and not time-sensitive (e.g. concerning malignancies) surgeries should be avoided during the pandemic. ${ }^{5,8,9}$ Particularly, endonasal endoscopic sinonasal surgery and laryngological surgery (especially jet ventilated) appear to be the riskiest procedures . Ideally, COVID-19 status should be determined preoperatively. In case of an elective but timesensitive surgery, advice should be given to all COVID-19-negative patients for social distancing and hand hygiene between the testing time and the time of surgery. ${ }^{12}$

During the pandemic, all recommended staff protection measures must be implemented. In particular, full PPE should be used not only in COVID-19 positive or high suspicious patients, but in COVID-19 negative or asymptomatic patients as well. In some reports, PAPR system (powered air purifying respirators) is recommended. High-risk operations or operations in COVID-19-positive patients should be performed in a designated operating room with negative pressures in which the smallest possible surgical team should be used both for reasons of safety and to preserve PPE. ${ }^{1,2}$

When performing the surgery, the use of powered devises (eg., drills, microdebriders) or ultrasonic shears should be avoided, since they may cause aerosolization of blood and other tissues. Even the use of electrocautery may be a risk factor for transmitting the virus via surgical smoke, although the infectiousness of aerosolized blood with SARS-CoV-2 is not yet known. Hence, it is advisable to keep the power settings of electrocautery as low as possible.

In patients positive to COVID-19, the surgery should be postponed [4]. In case that the surgery cannot be postponed, then the use of PAPR (Powered Air Purifying Respirators) additional to the appropriate PPE by all the surgery room staff is recommended. Alternatively, an external approach is chosen if possible [4]. If the patient is COVID-19 negative, the appropriate staff protection measures are needed [4]. The same applies to the surgical management of epistaxis. The use of powered instruments like shaver and/or drill should be limited or even avoided whenever possible.

Due to the amount of droplets and aerosols produced, tracheostomy and tracheostomy postoperative care (tracheostomy evaluation, suctioning, wound and tube changes, etc.) in COVID-19 patients is associated with a very high transmission risk to the entire health care team.Except in extremely urgent cases, it is essential to determine the COVID-19 status of the patient preoperatively.

The COVID-19 pandemic is an extraordinary challenge for the medical community. Since the SARS-CoV-2 virus has already expanded in the community in many countries of the world, each patient in which COVID-19 status cannot be confirmed should be managed as positive. Even if in many countries the pandemic is slowing down and medical practice is been adapted to new normality, a new pandemic wave in the upcoming winter is a possibility. Therefore, the way we practice medicine during the present or a new COVID-19 pandemic has to be based on scientific data and evidence. Otolaryngologists and surrounding staff are particularly at risk for COVID-19 infection. As with all health care professionals, their protection is essential for avoiding collapse of the health care system.

\section{Professor Dr. Shaikh Nurul Fattah Rumi}

Professor and Head, Department of ENT, Dhaka Medical College, Dhaka

DOI: https://doi.org/ 10.3329/jdmc.v29i2.51180 J Dhaka Med Coll. 2020; 29(2) : 92-94 


\section{References}

1. American Academy of Otolaryngology-Head and Neck Surgery (AAO-HNS) (2020), New Recommendations Regarding Urgent and Nonurgent Patient Care, https://www.entnet.org/content/newrecommendations-regarding-urgent-and-nonurgentpatient-care. Accessed 31 May 2020

2. The Australian Society of Otolaryngology Head and Neck Surgery (ASOHNS) (2020) Australian Guidance for ENT surgeons during the COVID-19 pandemic, https://asohns.org.au/about-us/newsand-announcements $/$ latest-news? article $=78$. Accessed 31 May 2020

3. American Academy of Otolaryngology-Head and Neck Surgery (AAO-HNS) (2020) Otolaryngologists and the COVID-19 Pandemic. https://www.entnet.org/ content/otolaryngologists-and-covid-19-pandemic. Accessed 31 May 2020

4. Patel ZM, Fernandez-Miranda J, Hwang PH, et al., (2020) Precautions for endoscopic transnasal skull base surgery during the covid-19 pandemic., https:/ /www.entnet.org/sites/default/files/uploads/covid19_endosb_lettertoeditor_neurosurgery_update3.23.20.pdf. [PMC free article] [PubMed]

5. DGHNO-KHC, BVHNO (2020) Gemeinsame Empfehlungen der DGHNO-KHC und des HNO-BV Warnung der Präsidien der HNO-Verbände, https:/ /www.hno.org/de/corona Accessed 21 March 2020
6. WHO, WHO Virtual press conference on COVID-19 (2020).https://www.who.int/emergencies/diseases/ novel-coronavirus-2019/media-resources / pressbriefings. Accessed 11 March 2020

7. DGHNO-KHC, BVHNO (2020) Aktuelle Informationen zum Thema Pragmatischer Personalschutz" durch Schutzmasken/Visiere außerhalb von krankenhausspezifischen Covid-19-Isolationsund OP-Bereichen von Seiten der DGHNO-KHC und des BVHNO https://cdn.hno.org/media/Corona-Ticker/ Pragmatischer_Personalschutz_Info_DGHNO_BVHNO_3003-20.pdf. Accessed 31 May 2020

8. van Doremalen N, Bushmaker T, Morris DH, et al. Aerosol and Surface Stability of SARS-CoV-2 as Compared with SARS-CoV-1. N Engl J Med. 2020;382:1564-1567. doi: 10.1056/NEJMc 2004973. [PMC free article] [PubMed] [CrossRef] [Google Scholar]

9. World Health Organization (2020) "Modes of transmission of the COVID-19 virus, Geneva: World Health Organization, Vols. https://www.who.int/ news-room/commentaries/detail/modes-oftransmission-of-virus-causing-covid-19implications-for-ipc-precaution-recommendations. Accessed 31 May 2020.

10. Lüers JC, Klußmann JP, Guntinas-Lichius O. The Covid-19 pandemic and otolaryngology: what it comes down to? Laryngo-Rhino-Otol. 2020 doi: 10.1055/a1095-2344. [PubMed] [CrossRef] [Google Scholar] 